\title{
O poder de polícia no processo eleitoral
}

Jaime de Aquino Júnior ${ }^{1}$

\section{Resumo}

O presente trabalho tem por escopo identificar as principais hipóteses onde há incidência do poder de polícia no processo eleitoral brasileiro através da análise de julgados e da legislação pertinente, atualmente em vigor, especialmente no que se refere ao Código Eleitoral Brasileiro, Lei 4.737/65, sempre em consonância com os princípios elencados na Constituição Federal de 1988.

Palavras Chave: Poder de Polícia; Direito Eleitoral; Processo Eleitoral.

\section{Introdução}

Poder de polícia é a prerrogativa concedida à Administração Pública objetivando restringir e/ou condicionar certos atos praticados por particulares que se revelem contrários ao interesse coletivo, ou até mesmo nocivos ao próprio Estado.

Nesse sentido, busca-se aqui discorrer sobre o tema, suas características e peculiaridades, bem como identificar as principais hipóteses em que incidirá no processo eleitoral através da análise da jurisprudência e da legislação pertinente em vigor, com enfoque no Código Eleitoral Brasileiro de 1965.

\section{Poder de polícia}

Embora existam algumas ponderações acerca do tema, dentre as quais muito se discute a pertinência de sua nomenclatura e hipóteses de incidência, poder de polícia é muito bem conceituado por Mello como sendo

a atividade da Administração Pública, expressa em atos normativos ou concretos, de condicionar, com fundamento em sua supremacia geral e na forma da lei, a liberdade e a propriedade dos indivíduos, mediante ação ora fiscalizadora, ora preventiva, ora repressiva, impondo coercitivamente aos particulares um dever de

1 Aluno do curso de Especialização em Direito do Estado da Universidade Estadual de Londrina. Artigo apresentado como requisito parcial à obtenção do título de especialista, sob a orientação do Prof. Dr. Marcos Antônio Striquer Soares. 
abstenção ('non facere') a fim de conformar-lhes os comportamentos aos interesses sociais consagrados no sistema normativo. (2004, p. 733).

O referido autor entende por ser infeliz o designativo do tema, visto por trazer consigo a "evocação de uma época pretérita" onde havia confusão entre Estado de Polícia com Estado de Direito, aludindo que de maior pertinência seria a substituição de tal nomenclatura por "limitações administrativas à liberdade e à propriedade" (MELLO, 2004, p. 717) ou mesmo pelo termo "polícia administrativa" (2004, p. 718).

Não obstante a isso, a legislação pátria também tratou do tema e aquela terminologia adotou ao assim conceituar, poder de polícia, no Código Tributário Nacional, Lei 5.172/66, in verbis:

\begin{abstract}
Art. 78. considera-se poder de polícia a atividade da administração pública que, limitando ou disciplinando direito, interesse ou liberdade, regula a prática de ato ou abstenção de fato, em razão de interesse público concernente à segurança, à higiene, à ordem, aos costumes, à disciplina da produção e do mercado, ao exercício de atividades econômicas dependentes de concessão ou autorização do Poder Público, à tranqüilidade pública ou ao respeito à propriedade e aos direitos individuais ou coletivos
\end{abstract}

Em regra, o poder de polícia caracteriza-se pela imposição de abstenções aos particulares em prol de uma coletividade; portanto, sua idéia predominante é a de vedação de um comportamento. Contudo, também possui importante caráter fiscalizador.

Pode-se dizer que tais poderes são contingentes e instrumentais da Administração Pública e que se efetivam na medida em que são condizentes com as exigências do serviço público e com os interesses coletivos.

Portanto, sob a invocação de tal poder, não se permite que liberdades públicas ou direitos fundamentais dos indivíduos, assegurados na Constituição Federal, sejam anulados ou simplesmente não observados pelas autoridades competentes. (MEIRELLES, 2003, p. 126129).

Confusão comumente encontrada refere-se à distinção entre as terminologias poder de polícia e polícia judiciária, sendo que a primeira, conforme já mencionado, possui como regra geral caráter preventivo, ao passo em que na segunda, o escopo é repressivo.

Isso não obsta, destarte, que a Administração Pública, no exercício regular do poder de polícia, atue de forma repressiva naquelas hipóteses em que a atividade danosa 
encontra-se em pleno curso, ou seja, onde tenha se revelado nociva ao interesse público durante sua consecução.

Nesse sentido, a atuação administrativa, segundo Mello (2004, p. 730), "marca-se pela repressão a uma atuação anti-social", e "só se poderá considerá-la preventiva relativamente, isto é, em relação aos futuros danos outros que adviriam da persistência do comportamento reprimido".

Assim, conclui o festejado autor que através do poder de polícia se predispõe unicamente a impedir ou paralisar atividades anti-sociais enquanto que na polícia judiciária, o que se preordena é a responsabilização dos violadores da ordem jurídica.

Vale dizer também que, ao passo em que a polícia judiciária se vale unicamente da legislação processual penal, a polícia administrativa, ou poder de polícia, se manifesta por meio de atos normativos e de alcance geral.

Outra importante observação a ser registrada tange no sentido de se caracterizar a incidência do poder de polícia, ora por meio de atos de competência discricionária, ora através de atos vinculados.

Os atos de competência vinculada existirão sempre quando a norma jurídica impuser aos agentes a forma de agir, sem que Ihes restem quaisquer faculdades quando de sua atuação. No dizer de Moraes, "o ato administrativo vinculado depende da ocorrência de todos os pressupostos previstos em lei. Trata-se do chamado ato administrativo vinculado". (2002, p.132).

Discricionária será aquela competência onde a atuação administrativa está eivada de vontade subjetiva, não obstante alguns requisitos a serem observados.

Nos atos administrativos discricionários, a lei concede de modo explicito ou implícito um maior grau de liberdade de atuação. E tal liberdade, deverá ser feita não apenas conforme a lei autoriza, mas também por meio de critérios de conveniência e oportunidade do administrador. (MORAES, 2002, p. 133).

No mesmo sentido, Spitzcovsky de forma clara e sucinta diferencia poder vinculado de discricionário, sendo o primeiro

aquele em que o agente fica inteiramente preso ao enunciado da lei, que, de resto, estabelece o único comportamento a ser adotado em situações concretas, não deixando nenhuma margem de liberdade para uma apreciação subjetiva pelo administrador. (2005, p. 82). 
E, o segundo, pode ser definido "como sendo aquele em que o agente também fica preso ao enunciado da lei, que, no entanto, não estabelece um único comportamento a ser adotado por ele em situações concretas". (SPITZCOVSKY, 2005, p. 82- 83).

O poder de polícia é um ato administrativo; e como tal, está adstrito ao ordenamento jurídico que regula as atividades da Administração, bem como sujeita-se ao controle de legalidade por parte do Poder Judiciário.

Insurge, neste contexto, a possibilidade de se invocar o Poder Judiciário visando coibir eventuais excessos por parte daquele incumbido pela Administração Pública que, diante de uma situação em que a discricionariedade se encontre presente, não está adstrito ao cometimento de abusos.

Vale ressaltar que tal ingerência do Poder Judiciário não se destina a interferir nos assuntos administrativos, e sim tão somente zelar pela ordem, sem que haja detrimento ao interesse público, em casos de eventuais extrapolações e por que não, ilegalidades cometidas.

Mas, em sendo o poder de polícia uma atribuição da Administração Pública cujos eventuais excessos podem ser coibidos pelo Poder Judiciário, caso este seja provocado, compete também ao Judiciário atos e decisões sobre a forma de um poder de polícia?

Entende-se que sim. Os atos e decisões judiciais podem ser revestidos do poder de polícia na medida em que restrinjam ou suspendam a realização e/ou continuidade de situações em contraste com o interesse público.

Nesse sentido, passaremos a analisar a incidência do poder de polícia no processo eleitoral.

\section{Processo eleitoral}

Em um primeiro momento, torna-se importante uma breve distinção entre direito material e processual.

Segundo ensina Cintra, "direito material é o corpo de normas que disciplinam as relações jurídicas referentes a bens e utilidades da vida", tais como o direito civil, o penal, administrativo, eleitoral, etc. Enquanto que, direito processual, é, assim, "um instrumento a serviço do direito material". (1998, p. 40). 
Direito processual é, portanto, um instrumento do direito substantivo ou material. É um direito adjetivo, ou formal, que regula a aplicação do direito material aos casos concretos, disciplinando a criação de normas jurídicas individuais.

Disciplina também, conforme ensina Diniz, "a atividade dos juízes, dos tribunais ou órgãos encarregados da distribuição da justiça, determinando como devem agir para fazer cumprir a lei que foi violada". (2003, p. 260).

Nesse sentido, o direito processual eleitoral, por sua vez, é regido, em grande parte, pelo Código Eleitoral, Lei 4.737 de 15 de julho de 1965.

Porém, o Código Eleitoral não é a única fonte do direito processual eleitoral, valendo-se também, os juízes e tribunais eleitorais de diversos outros normativos, tais como Resoluções expedidas pelo Tribunal Superior Eleitoral, TSE, pelos Tribunais Regionais Eleitorais dos Estados e Distrito Federal, TRE's, além de outras leis ordinárias, merecendo destaque a Lei 9.504/97 que estabelece normas para as eleições.

Dentre outros dispositivos legais de relevante importância, podem ser citadas a Lei 6.091/74, que dispõe sobre o fornecimento gratuito de transporte em dias de eleição a eleitores residentes nas zonas rurais, e dá outras providências; e a Lei Complementar n.ㅇ 64, de 18 de maio de 1990, que estabelece, de acordo com o art. 14, § 9 o da Constituição Federal, casos de inelegibilidade, prazos de cessação, bem como determina outras providências.

O processo eleitoral compreende diversas etapas, abrangendo desde a composição de seus tribunais e juntas, procedimentos de alistamento eleitoral, registro de candidatos, atos preparatórios para votação, procedimentos a serem adotados quando da apuração, dentre tantos outros, regendo até os mais variados recursos dirigidos aos tribunais.

Caracteriza-se, portanto, o processo eleitoral, por ser vasta e complexamente positivado, quase não restando margem a analogia bem como a outras formas de integração do direito.

Nesse contexto, seria possível a incidência do poder de polícia no processo eleitoral, já que dentre as características daquele vislumbra-se a discricionariedade?

Certamente que sim, conforme se passará a analisar, já que o poder de polícia não significa uma afronta aos normativos pré-existentes. 


\section{0 poder de polícia no processo eleitoral}

O poder de polícia não é somente admissível ao processo eleitoral, mas de suma importância como uma de suas formas de instrumentalidade.

Assim, conforme preconiza o artigo 139 do Código Eleitoral, ao presidente da mesa receptora e ao juiz eleitoral caberá a polícia dos trabalhos eleitorais.

O juiz eleitoral é figura de extrema importância nesse contexto, pois a ele competirá, na esmagadora maioria das vezes, o uso do poder de polícia.

Dentre as hipóteses mais simples onde se visualiza a atuação jurisdicional através do poder de polícia, podem ser citadas:

\footnotetext{
Código Eleitoral, Lei 4.737/65

Art. 35. Compete aos juízes:

[...]

IV - fazer as diligências que julgar necessárias à ordem e presteza do serviço eleitoral;"

Do alistamento

Art. 45. [...]

$\S$ 2. Poderá o juiz se tiver duvida quanto à identidade do requerente ou sobre qualquer outro requisito para o alistamento, converter o julgamento em diligencia para que o alistando esclareça ou complete a prova ou, se for necessário, compareça pessoalmente à sua presença.

Da fiscalização perante as mesas receptoras

Art. $131[\ldots]$

§ 4. P Para esse fim, o delegado do partido encaminhará as credenciais ao Cartório, juntamente com os títulos eleitorais dos fiscais credenciados, para que, verificado pelo escrivão que as inscrições correspondentes aos títulos estão em vigor e se referem aos nomeados, carimbe as credenciais e as apresente ao juiz para o visto". Do encerramento da votação

Art. $154[\ldots]$

$\S 2$. . No Distrito Federal e nas capitais dos Estados poderão os Tribunais Regionais determinar normas diversas para a entrega de urnas e papéis eleitorais, com as cautelas destinadas a evitar violação ou extravio". (BRASIL, Lei n. 4737 de 15 de julho de 1965.
}

Há, conforme elencado e outras mais, diversas hipóteses de incidência do poder de polícia no processo eleitoral, embora nem todas sejam merecedoras de comentários; não por menor importância, mas sim por menor relevância.

Porém, é na propaganda eleitoral onde o poder de polícia servirá ao juiz eleitoral de forma mais contundente, mais precisa, visando sempre resguardar o interesse, a ordem pública.

Nesse sentido, dispõe o artigo 249 do Código Eleitoral: 
Art. 249. O direito de propaganda não importa restrição ao poder de policia quando este deva ser exercido em benefício da ordem pública.

No que tange à propaganda eleitoral, suas principais disposições regulamentadoras encontram-se no Título III da Quinta parte do Código Eleitoral, bem como no artigo 36 e seguintes da Lei 9.504/97.

A propaganda partidária também é disciplinada, em parte, pela Lei 9.096/95, lei esta que dispõe sobre partidos políticos e regulamenta os artigos 17 e 14, § 3으, inciso V, da Constituição Federal; onde, a partir do artigo 45, dispõe sobre o acesso gratuito ao rádio e à televisão.

Tais dispositivos versam sobre as mais variadas formas de propaganda eleitoral, sejam no que se referem às datas em que são permitidas, às penalidades passíveis de aplicação, quanto à exigência ou não de autorização para sua veiculação; regulamentam também a propaganda eleitoral mediante outdoors, na imprensa, no rádio e televisão.

Os normativos citados são ricos em detalhes; e visam, com isso, garantir isonomia entre os partidos políticos e impossibilitar o cometimento de abusos e arbitrariedades, não somente contrárias à ordem pública, mas também no sentido de evitar possíveis distorções que acabam por ludibriar os eleitores.

Assim, os abusos praticados sujeitam seus autores e demais responsáveis às penalidades aplicáveis perante a justiça eleitoral. Surge, então, o poder de polícia, como importante instrumento do qual se valerá o juiz eleitoral visando coibir as irregularidades cometidas.

Nesse sentido, dispõe a jurisprudência do Tribunal Superior Eleitoral, in verbis:

EMENTA: ELEITORAL. PROPAGANDA IRREGULAR. JUSTICA ELEITORAL. PODER DE POLÍCIA. CODIGO ELEITORAL, ART. 347. RECURSO: PREQUESTIONAMENTO.

I- O descumprimento de ordem da Justiça Eleitoral, no exercício do poder de polícia, sujeita os infratores às penas do art. 347 do Código Eleitoral. II- Ausência de dissídio jurisprudencial ou normativo.

III- Recurso Especial não conhecido.

(TSE - RESPE - RECURSO ESPECIAL ELEITORAL n.ํ 10984 - RS -Relator Min. Carlos Mário da Silva Velloso - Publicado no DJ em 26/11/1993, Página 25.589. Disponível em: <http://www.tse.gov.br/servicos/jurisprudencia/index.html>

Acesso em: 11 janeiro 2006.).

Conforme já mencionado, a discricionariedade é uma das principais características do poder de polícia. 
Como tal, remete a idéia de o juiz agirá de ofício naquelas situações onde são constatados abusos e/ou irregularidades.

Porém, esta afirmativa, por si só, não é verídica, pois, embora haja um maior grau de liberdade de atuação do magistrado em tais hipóteses, nem sempre poderá ele atuar por impulso próprio.

Há um entendimento firmado de que para agir, mesmo quando no exercício do poder de polícia, deverá o juiz eleitoral ser provocado, ou seja, somente agirá se requerido o for pelas partes, ou pelo Ministério Público Eleitoral.

Nesse caso, evidencia-se a observância do que a doutrina denomina de princípio da ação.

O princípio em referência é aplicado no direito processual civil, no processual penal e, no processo eleitoral, não poderia ser diferente.

Cintra assim o define:

Princípio da ação, ou princípio da demanda, indica a atribuição à parte da iniciativa de provocar o exercício da função jurisdicional. [...] A jurisdição é inerte e, para sua movimentação, exige a provocação do interessado. É a isto que se denomina principio da ação: nemo iudex sine actore. (1998, p. 57-58).

Complementa o festejado doutrinador dizendo que o juiz que instaura o processo, por iniciativa própria, acabaria ligado psicologicamente à pretensão, colocando-se em posição propensa a julgar favoravelmente a ela. Dessa forma, a finalidade do princípio em questão seria justamente a de garantir um outro princípio, o da imparcialidade. (op. cit. p. 58).

Assim, poderá agir o juiz eleitoral no exercício do poder de polícia sim, porém, quando provocado por quem de interesse; seja por uma das partes ou inclusive pelo Ministério Público Eleitoral.

Nesse sentido, assim dispõe a jurisprudência do Tribunal Superior Eleitoral:

EMENTA: PROPAGANDA ELEITORAL IRREGULAR. AFIXACAO DE CARTAZES EM ARVORES DO PATRIMONIO PUBLICO. OFENSA A LEI 9.504/97. JUIZES ELEITORAIS. PODER DE POLÍCIA. ILEGITIMIDADE ATIVA.

1. É vedada a realização de propaganda eleitoral em árvores do patrimônio público. 2. Nos termos da Lei n. 9.504/97, art. 96, parágrafo 3, compete ao juiz auxilia julgar as representações ou reclamações que tenham por objeto o não cumprimento 
desse diploma legal. Todavia, não lhe é permitido instaurar o processo de ofício. 3. Processo extinto.

(TSE - RESPE - Recurso Especial Eleitoral n. 16.187 - SP - Relator Min. Edson Carvalho Vidigal - Publicado no DJ em 24/03/2000, Página 123. Disponível em: <http://www.tse.gov.br/servicos/jurisprudencia/index.html> Acesso em: 11 janeiro 2006.).

No mesmo sentido,

EMENTA: PROPAGANDA ELEITORAL. AFIXACAO DE CARTAZES EM ARVORES DO PATRIMONIO PUBLICO. INFRACAO.

Hipótese, entretanto, em que, conhecido o recurso, a aplicação do direito à espécie conduz a extinção do processo, por falta de legitimidade de quem determinou sua instauração. Cabe aos juízes eleitorais, no exercício do poder de polícia, fazer cessar a prática contrária a lei. Para aplicação de sanções, entretanto, mister a instauração do procedimento, por iniciativa dos para isso legitimados.

(TSE - RESPE - Recurso Especial Eleitoral n. 16.028 - SP - Relator Min. Eduardo Andrade Ribeiro de Oliveira - Publicado no DJ em 10/09/1999, Página 66. Disponível em: <http://www.tse.gov.br/servicos/jurisprudencia/index.html> Acesso em: 11 janeiro 2006.).

Outra observação importante a ser registrada refere-se ainda à iniciativa que requer a instauração de procedimento ao magistrado eleitoral.

Compete sim às partes, bem como ao Ministério Público, requerer providencias ao juiz eleitoral, em face às irregularidades constatadas. Porém, a qualquer cidadão caberá denunciar o conhecimento de práticas ilegais, para as quais o juiz, se entender necessário, requisitará o pronunciamento do parquet para que este, entendendo necessário, represente perante o juízo competente.

Assim, já se decidiu o TSE:

EMENTA: RECURSO INOMINADO PARCIAL. PROPAGANDA ELEITORAL. ILEGITIMIDADE DA CORREGEDORIA GERAL ELEITORAL E DO MINISTERIO PUBLICO. PRELIMINAR ACOLHIDA PELA SENTENCA QUE JULGOU IMPROCEDENTE A ACAO.

1. O Ministério Público, instituição permanente, essencial à função jurisdicional do Estado e a defesa da ordem jurídica e do regime democrático, é competente para atuar em todas as fases e instancias do processo eleitoral, tendo legitimidade para promover a apuração dos fatos e oferecer representação, tendo em vista a fiel observância das leis eleitorais e sua aplicação uniforme em todo o país.

2. Notícias de jornais. Comunicação ao Corregedor-Geral Eleitoral por servidora do Tribunal. Irrelevância.

2.1. Não há qualquer vício na iniciativa de servidora que noticia as publicações à autoridade competente para requisitar o pronunciamento do Ministério Público. A participação da servidora limitou-se a notitia dos fatos, sobre os quais o Ministério Público, se entendesse relevantes, ofereceria representação. 
3. Corregedoria Geral Eleitoral. Poder de polícia. Compete à Justiça Eleitoral, através da Corregedoria Geral Eleitoral ou Regional, realizar investigações sobre fatos que the chegam ao conhecimento, a fim de que possam ser apreciados no resguardo da lisura do processo eleitoral (CE, Artigo 356).

4. Propaganda eleitoral irregular. Improcedência da representação. Recurso Inominado. Trânsito em julgado do mérito da controvérsia. Interesse jurídico inexistente. Ausência do requisito utilidade/necessidade da prestação jurisdicional requerida. Recurso Inominado não conhecido.

(TSE - RRP - Recurso em Representação n. 39 - Brasília DF - Relator Min. Maurício José Corrêa - Publicado no DJ em 25/09/1998, Página 68. Disponível em: <http://www.tse.gov.br/servicos/jurisprudencia/index.html> Acesso em: 11 janeiro 2006.).

Pelo exposto até então, verificou-se a plena possibilidade da atuação jurisdicional através do poder de polícia; sendo necessária a provocação pela parte interessada.

Porém, não será sempre que a atuação do juiz eleitoral estará adstrita à iniciativa da partes.

O intuito em prescindir a atuação ex officio do magistrado eleitoral é justamente resguardar sua imparcialidade, consoante ao já exposto no conceito de princípio da ação.

Assim, indubitavelmente, competirá ao juiz eleitoral atuar, no exercício do poder de polícia, de oficio; ou seja, sem que haja provocação das partes e/ou Ministério Público, quando seu ato não implicar sanção.

Desse modo, o princípio da imparcialidade não deixaria de estar sendo observado; inexistindo qualquer ilegalidade.

Este entendimento foi acolhido pelo TSE, conforme julgamento cuja transcrição se torna oportuna:

EMENTA: RECURSO EM MANDADO DE SEGURANÇA - AFIXAÇÃO DE PLACAS EM PASSARELAS E VIADUTOS - MINIDOOR - DETERMINAÇÃO PARA RETIRADA COORDENAÇÃO DE FISCALIZAÇÃO DA PROPAGANDA ELEITORAL - POSSIBILIDADE.

1. Não viola o art. 17, § 1으, da Res./TSE no 20.951 a determinação de retirada de propaganda eleitoral pela Coordenação de Fiscalização da Propaganda Eleitoral, se não existe aplicação da sanção.

2. O poder de polícia, que não depende de provocação, deve ser exercido quando o juiz eleitoral considerar haver irregularidade, perigo de dano ao bem público ou ao bom andamento do tráfego.

3. A regularidade da propaganda não pode ser examinada em sede de mandado de segurança, por demandar produção e exame de provas.

(TSE - RMS - Recurso em Mandado de Segurança n. 242 - Belo Horizonte MG Relator Min. Fernando Neves da Silva - Publicado no DJ, Volume 1, em 13/12/2002, Página $210 . \quad$ Disponível em: <http://www.tse.gov.br/servicos/jurisprudencia/index.html> Acesso em: 11 janeiro 2006.). 
Desse modo, o princípio da imparcialidade não deixaria de estar sendo observado; inexistindo qualquer ilegalidade.

\section{Conclusão}

Conforme se procurou demonstrar, algumas divergências podem emergir ao se tratar do tema relativo ao poder de polícia no processo eleitoral, como sua própria possibilidade de incidência, dentre outras circunstancias que tangem o assunto.

Contudo, tornou-se possível identificar na legislação e na jurisprudência, dispositivos onde o exercício do poder de polícia é, sem dúvida alguma, plenamente possível e aplicável.

Poderá valer-se sim, do poder de polícia, sempre que necessário, porém, observado o princípio processual da ação, onde para agir deverá ser provocado pela parte ou Ministério Público; como também agir de ofício nos casos em que não envolver aplicação de sanção.

Diante disso, conclui-se que o poder de polícia no processo eleitoral não é tão somente uma prerrogativa do magistrado, mas um instrumento pleno e capaz através do qual o juiz eleitoral auferirá meios suficientes para sanar irregularidades bem como coibir abusos, visando assim, sempre, resguardar a ordem e o interesse público.

\section{Referências}

BRASIL. Lei no 4737, de 15 de julho de 1965. Institui o Código Eleitoral. Disponível em: <https://www.planalto.gov.br/> Acesso em: 29 ago. 2005.

Lei no 5172, de 25 de outubro de 1966. Dispõe sobre o Sistema Tributário Nacional e institui normas gerais de direito tributário aplicáveis à União, Estados e Municípios. In: FRANCO, Vera Helena de Mello; CARRAZZA, Roque Antônio (Org.). Código comercial, código tributário nacional, constituição federal. 5. ed. atual. São Paulo: Editora Revista dos Tribunais, 2003. p. 82.

Lei no 6091, de 15 de agosto de 1974. Dispõe sobre o fornecimento gratuito de transporte, em dias de eleição, a eleitores residentes nas zonas rurais, e dá outras providências. Disponível em: <https://www.planalto.gov.br/> Acesso em: 29 ago. 2005. . Constituição (1988). Constituição da República Federativa do Brasil. Brasília, DF, 1988. 
. Lei Complementar no 64, de 18 de maio de 1990. Estabelece, de acordo com o art. $14, \S 90$ da Constituição Federal, casos de inelegibilidade, prazos de cessação, e determina outras providências. Disponível em: <https://www.planalto.gov.br/> Acesso em: 29 ago. 2005.

. Lei no 9096, de 19 de setembro de 1995. Dispõe sobre partidos políticos, regulamenta os arts. 17 e 14, § 3으, inciso V, da Constituição Federal. Disponível em: <https://www.planalto.gov.br/> Acesso em: 29 ago. 2005.

Lei no 9504, de 30 de setembro de 1997. Estabelece normas para as eleições. Disponível em: <https://www.planalto.gov.br/> Acesso em: 29 ago. 2005.

Tribunal Superior Eleitoral (Site). Disponível em:

<http://www.tse.gov.br/servicos/jurisprudencia/index.html> Acesso em: 11 jan.o 2006.

CINTRA, Antonio Carlos de Araújo. Teoria geral do processo. 14. ed. São Paulo: Malheiros Editores, 1998.

DINIZ, Maria Helena. Compêndio de introdução à ciência do direito. 15. ed. São Paulo: Saraiva, 2003.

MEIRELLES, Hely Lopes. Direito administrativo brasileiro. 28. ed. São Paulo: Malheiros, 2003.

MELLO, Celso Antônio Bandeira de. Curso de direito administrativo. 17. ed. São Paulo: Malheiros, 2004.

MORAES, Alexandre de. Direito constitucional administrativo. São Paulo: Atlas, 2002.

MÜLLER, Mary Stela; CORNELSEN, Julce Mary. Normas e padrões para teses, dissertações e monografias. 5. ed. Londrina: Eduel, 2003.

SPITZCOVSKY, Celso. Direito Administrativo. 7. ed. São Paulo: Damásio de Jesus, 2005. 